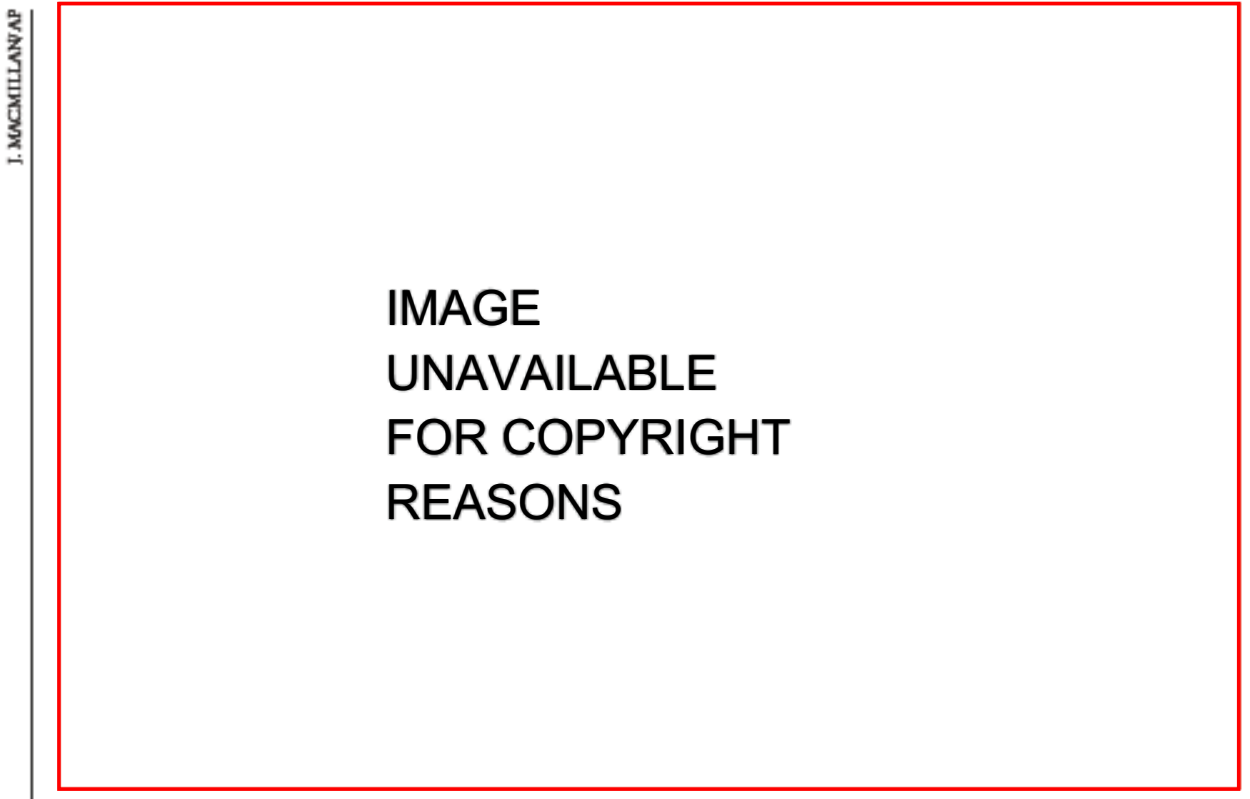

An atmosphere of fear could have deterred former Iraqi weapons scientists from coming forward.

\title{
US bungled investigation into weapons research in Iraq
}

Jim Giles, London, and Geoff Brumfiel, Washington

Flawed interrogations of scientists in the aftermath of the Iraqi war hampered investigations of the country's weapons of mass destruction (WMD) programme and added to the risk that knowledge and technology would spread to neighbouring countries, US government advisers have concluded.

Iraqi researchers willing to cooperate with the United States were detained without cause while key WMD individuals were never targeted or even identified, according to new information released by the Iraq SurveyGroup (ISG). The ISG is a team of British, American and Australian inspectors charged with finding WMD after the fall of Saddam Hussein's regime. Coalition policies also created an atmosphere of fear that deterred potentially helpful researchers from talking and increased the likelihood that WMD scientists might defect to neighbouring states such as Iran or Syria, or find work with insurgent forces in Iraq, the authors said in a report released on 25 April.

"This report is being honest," says David Albright, a former United Nations weapons inspector and president of the Institute for Science and International Security in Washington DC. ${ }^{\alpha}$ The search was horribly mismanaged. The military treated scientists as common criminals."

Albrightraised concerns soon after Baghdad fell to US forces, two years ago last month. $\mathrm{He}$ and other non-proliferation experts complained that Iraqi scientists were reluctant to cooper ate for fear of being taken prisoner and wanted protection from prosecution before they would talk (see Nature 423,$371 ; 2003$ ). The ISG has now acknowledged these problems.

The public listing of the 55 most-wanted members of Hussein's regime is one tactic singled out for criticism. This left other Iraqis uncertain as to whether they were on a longer blacklist that included 300 names. As many Iraqis were at the time being detained for a wide range of reasons, "these factors combined to cause Iraq WMD participants at virtually all levels to attempt to remain undetected,"the ISG says.

Those that were detained were often subject to bungled interrogation, the authors add. They found that army interrogators, who lacked technical training, glossed over key details when interviewing detainees and created inconsistent and sometimes errorfilled intelligence briefs. WMD experts involved in the interviews usually onlystayed in Baghdad for a month or two, often leaving just as they were gaining knowledge useful to the ISG investigation.

The ISG stresses that there is no evidence that defectors to neighbouring "hostile states" are actually working on WMD. But it adds that there are many reports of "Iraqis with general chemical or biological expertise helping insurgents to produce chemical and biological agents".

Around 100 of the 300 blacklisted individuals are still being detained. ${ }^{*}$ As far as the WMD investigation is concerned, there is no further purpose in holding many of these individuals," the report concludes.
Rethink on review leaves researchers out in the cold

Geoff Brumfiel, Washington

US researchers could increasingly find that their grant applications are rejected without even being seen by fundingagency reviewers. The situation has arisen because the National Sdence Foundation (NSF) is asking universities to pre-screen some types of proposal in a bid to cut down its workload.

The NSF is responsible for funding the majority of US university-based, nonbiomedical research. It has a sterling reputation among scientists for using peer review to determine who should receive grant money. But in the face of tight budget constraints, it is trying to shift some of that responsibility onto individual universities.

In the past few years, the NSF has placed limits on the number of applications that a single institution can submit. Those limits will now become increasingly common, according to Arden Bement, the agency's director. He says the measures are needed to control the number of proposals flooding in to his staff, and to boost the success rate of applications. He stresses that the new policy will affect only large facilities and collaborative grants. "This would not be for individual applications, ${ }^{n}$ he says.

But universities are starting to speak out about the proposals, warning that the changes are forcing them to become unwilling peer reviewers. Earlier this year, administrators at Princeton University, New Jersey, had to choose one of several proposals for a programme that funded international collaborations, according to Diane Jones, director of the university's office of government affairs. The proposals came from several disciplines and departments, making the choice far from straightforward. "Universities are not set up to do this kind of internal peer review," she says.

Fawwaz Ulaby, vice-president for research at the University of Michigan in Ann Arbor, adds that the rules particularly limit the opportunities for researchers at large universities. "They're doing this at the expense of fairness," he says.

But Bement says he has little choice in the face of a $2 \%$ budget cut this year. $\mathrm{He}$ adds that he still believes the agencies will receive the best proposals. "The universities will almost invariably put forward the ones of highest scientific merit, ${ }^{n}$ he says. 